\title{
Clinical Significance of Adrenal Computed Tomography in Addison's Disease
}

\author{
Zhong Hua SUN, KaOru NOMURA, Shohzoh TORAYA, \\ Makoto UJIHARA, Nobuo HORIBA, Toshihiro SUDA, \\ Toshio TSUSHIMA, Hiroshi DEMURA and Atsushi KONO \\ Department of Medicine, Institute of Clinical Endocrinology and \\ Department of Radiology, Tokyo Women's Medical College, \\ Tokyo 162, Japan
}

\begin{abstract}
Adrenal computed tomographic (CT) scanning was conducted in twelve patients with Addison's disease during the clinical course. In tuberculous Addison's disease $(n=8)$, three of four patients examined during the first two years after disease onset had bilaterally enlarged adrenals, while one of four had a unilaterally enlarged one. At least one adrenal gland was enlarged after onset in all six patients examined during the first four years. Thereafter, the adrenal glands may atrophy bilaterally, in contrast to adrenal glands in idiopathic Addison's disease, which atropy bilaterally from disease onset $(n=2)$. Adrenal calcification was a less sensitive clue in tracing pathogenesis, i.e., adrenal calcification was observed in five of eight patients with tuberculous Addison's disease, but not in idiopathic patients. Thus, adrenal CT scanning could show the etiology of Addison's disease (infection or autoimmunity) and the phase of Addison's disease secondary to tuberculosis, which may be clinically important for initiating antituberculous treatment.
\end{abstract}

Key words: Addison's disease, Tuberculosis, Idiopathic atrophy, CT. (Endocrinol Japon 39: 563-569, 1992)

SINCE Addison reported autopsy findings in persons with skin hyperpigmentation and adrenal gland disease in 1937, autopsy was, for a long time, the only way to examine the adrenal morphology of Addison's disease [1-3]. In Addison's disease due to tuberculosis, adrenal enlargement was in the form of a caseous necrotic granulomatous mass, and adrenal atrophy indicated complete destruction of the gland [1-3]. A promising technique has been computed tomographic (CT) scanning, which demonstrates morphological changes in either atrophic or enlarged glands [4-9]. McMurry et al. reported that two cases of tuberculous Addison's disease with recent onset had enlarged glands [5]. Based on a study involv-

Received: June 24, 1992

Accepted: September 18, 1992

Correspondence to: Dr. Kaoru NOMURA, Department of Medicine, Institute of Clinical Endocrinology, 'Tokyo Women's Medical College, 8-1 Kawada-cho, Shinjuku-ku, Tokyo 162, Japan. ing one CT scanning and seven autopsies, Vita et al. reported that seven of eight patients with tuberculous Addison's disease of no greater than two years' duration had enlarged glands, whereas patients with longer disease duration had smaller or normal-sized glands [9]. Conjecture about the time of adrenal disease onset may be clinically important because of potential recovery from adrenal insufficiency due to early treatment with antituberculous drugs $[10,11]$, or treatment for South American blastomycosis [12]. This study was designed to learn more about time-sequential changes from onset to later periods in tuberculous Addison's disease by means of CT $\mathrm{C}$ scanning, which has not yet been precisely examined. We also report CT findings on idiopathic Addison's disease at onset for the first time, to the best of our knowledge, which we found to be distinct from that in tuberculous Addison's disease and therefore to be useful for differential diagnosis. 


\section{Patients and Materials}

The twelve patients with Addison's disease studied had low plasma and urinary cortisol levels and a high plasma ACTH level. ACTH stimulation test failed to raise the plasma cortisol level. CT examination with a TOSHIBA TCT-60A or TCT$900 \mathrm{~S}$, with sections taken $0.5 \mathrm{~cm}$ apart and a scanning time of 4.5 or 2 sec, was performed. Adrenal gland size on CT scanning was measured at the section where the adrenal mass appeared largest. We judged that the gland was enlarged when it was wider than $2.5 \mathrm{~cm}$ or thicker than 1 $\mathrm{cm}$, based on the report of normal adrenal size in CT $\Gamma$ scanning [13]. The gland was judged to be atrophied when it was difficult to see or not visible.

Eight (patients 1-8) were clinically diagnosed as having Addison's disease due to tuberculosis and four (patients 9-12) due to idiopathic atrophy. Profiles were given in the sections that follow. Their CT findings are summarized in Table 1.

Patient 1. A 75-year-old female had weight loss and hyperpigmentation in 1983. Because she had pulmonary tuberculosis, a positive tuberculin test, and a fast erythrocyte sedimentation rate (ESR) in July, 1984, she was diagnosed as having Addison's disease secondary to tuberculosis, and treated with a hormonal supplement (hydrocortisone) and antituberculous therapy including isoniazid (INH), rifampicin (RFP), and streptomycin sulfate. Antituberculous therapy was stopped in March, 1985 due to adverse effects. A CT scan at that time indicated a retroperitoneal abscess, most likely tuberculous.

Table 1. Summary of patients examined

\begin{tabular}{|c|c|c|c|c|c|}
\hline \multirow{3}{*}{$\begin{array}{l}\text { Patient } \\
\text { No. }\end{array}$} & \multirow{3}{*}{ Etiology ${ }^{i 1)}$} & \multirow{3}{*}{$\mathrm{CT}$ scan } & \multirow{3}{*}{$\begin{array}{c}\text { Duration of } \\
\text { Addison's disease } \\
\text { (years) }\end{array}$} & \multicolumn{2}{|c|}{ CT findings } \\
\hline & & & & \multicolumn{2}{|c|}{$\begin{array}{c}\text { Adrenal gland size }(\mathrm{mm}) \\
\text { and calcification }\end{array}$} \\
\hline & & & & Left & Right \\
\hline \multirow[t]{4}{*}{1} & $\mathrm{~Tb}$ & 1984.7 & 1 & $22 \times 12$ & $34 \times 29$ \\
\hline & & 1985.5 & 2 & $24 \times 17$ & (b) \\
\hline & & 1987. 3 & 4 & $16 \times 14$ & (b) \\
\hline & & 1991. 7 & 8 & $13 \times 10$ & Atrophy \\
\hline 2 & $\mathrm{~Tb}$ & 1989. 4 & 2 & $20 \times 18 *$ & $15 \times 12 *$ \\
\hline 3 & $\mathrm{~Tb}$ & 1983. 1 & 1 & $12 \times 11$ & $18 \times 13$ \\
\hline \multirow[t]{4}{*}{4} & $\mathrm{~Tb}$ & 1981.10 & 2 & $16 \times 14 *$ & $21 \times(<10)$ \\
\hline & & 1983.3 & 4 & $13 \times 13 *$ & Atrophy \\
\hline & & 1986.2 & 7 & $13 \times 13 *$ & Atrophy \\
\hline & & 1992. 1 & 13 & $13 \times 13 *$ & Atrophy \\
\hline \multirow[t]{6}{*}{5} & $\mathrm{~Tb}$ & 1983. 2 & 3 & $21 \times 15$ & Atrophy * \\
\hline & & 1984. 10 & 4 & $18 \times 14 *$ & Atrophy * \\
\hline & & 1985. 11 & 5 & $12 \times 10 *$ & Atrophy * \\
\hline & & 1988.6 & 8 & $12 \times 10 *$ & Atrophy * \\
\hline & & 1989.2 & 9 & $12 \times 10 *$ & Atrophy * \\
\hline & & 1991.11 & 11 & $10 \times 10 *$ & Atrophy * \\
\hline \multirow[t]{5}{*}{6} & $\mathrm{~Tb}$ & 1985. 12 & 4 & $24 \times 14$ & Atrophy \\
\hline & & 1988. 4 & 7 & $25 \times 15$ & Atrophy \\
\hline & & 1989.3 & 8 & $25 \times 15$ & Atrophy \\
\hline & & 1990.2 & 9 & $25 \times 15 *$ & Atrophy \\
\hline & & 1991.3 & 10 & $25 \times 15 *$ & Atrophy \\
\hline 7 & $\mathrm{~Tb}$ & 1990.7 & 8 & Atrophy * & Atrophy * \\
\hline 8 & $\mathrm{~Tb}$ & 1989.3 & 16 & Atrophy & $10 \times 10$ \\
\hline 9 & Idiopathic & 1991. 7 & $<1$ & Atrophy & Atrophy \\
\hline 10 & Idiopathic & 1989.8 & $<1$ & Atrophy & Atrophy \\
\hline 11 & Idiopathic & 1992. 4 & 3 & Atrophy & Atrophy \\
\hline 12 & Idiopathic & 1987. 9 & 8 & Atrophy & Atrophy \\
\hline
\end{tabular}

*Adrenal calcification. "Tuberculous Addison's disease ( $\mathrm{Tb}$ ) or idiopathic Addison's disease (Idiopathic). "A retroperitoneal abscess formed connected with an adrenal abscess. The adrenal size could not be measured correctly. In July, 1991, the retroperitoneal abscess shrank until it was no longer connected with the adrenal gland, which was not visible. 
Patient 2. A 45-year-old male suffered caries of the spine at age two. From age 12, he underwent steroid ointment treatment for dermatitis. In February, 1987, he suffered from hyperpigmentation and lassitude, In April, 1987, he was diagnosed as having Addison's disease and was treated with hydrocortisone. Addison's disease was considered secondary to tuberculosis because of his medical history and adrenal calcification. He had a negative tuberculin test and CRP of $0 \mathrm{mg} / \mathrm{d} l$.

Patient 3. A 71-year-old male suffered from hyperpigmentation, lassitude, and weight loss in early 1982, and was diagnosed as having Addison's disease in December, 1982. Addison's disease was considered secondary to tuberculosis because he had had pulmonary tuberculosis at 25 and had slightly increased ESR. He was treated with hydrocortisone, INH, and RFP.

Patient 4. A 47-year-old male had had a noticeable salt craving since 1979, and thereafter suffered from skin and nail hyperpigmentation. He was diagnosed as having Addison's disease in September, 1981, and hormonal supplement (hydrocortisone) was started. Addison's disease was considered secondary to tuberculosis, a positive tuberculin test, and a calcified adrenal gland.

Patient 5. A 65-year-old female suffered from hyperpigmentation in 1980 and was diagnosed as having Addison's disease, after which she was treated with hydrocortisone. Because of a history of pulmonary tuberculosis in 1947 and adrenal calcification, Addison's disease was diagnosed secondary to tuberculosis.

Patient 6. A 79-year-old male suffered from hyperpigmentation in 1981. He was diagnosed as having Addison's disease and was treated with hydrocortisone from 1985 on. Because of a history of pulmonary tuberculosis in 1952, Addison's disease was diagnosed secondary to tuberculosis. His CRP was $1.1 \mathrm{mg} / \mathrm{d} l$.

Patient 7. A 53-year-old female suffered from hyperpigmentation and fatigue in 1982. In 1988, she was diagnosed as having renal tuberculosis and was treated with INH and RFP for a year. In April, 1990, she was diagnosed as having Addison's disease, and treated with hydrocortisone. Addison's disease was diagnosed as secondary to tuberculosis because of her past history of renal tuberculosis and adrenal calcification.

Patient 8. A 62-year-old male suffered from lassitude and poor appetite in 1973, and hyperpig- mentation and weight loss in 1976, He was diagnosed as suffering from Addison's disease, and treated with hydrocortisone from 1976. Addison's disease was diagnosed secondary to tuberculosis because of his history of pulmonary tuberculosis in 1948. In 1986, CRP was $0.1 \mathrm{mg} / \mathrm{d} l$ and tuberculin test negative,

Patient 9. A 30-year-old female suffered from chronic candidiasis of the skin and mucosa from age 3 , and from hypoparathyroidism from age 11 . She was diagnosed as having polyglandular autoimmune syndrome type 1 in 1987. In 1988, she was diagnosed as having insulin-dependent diabetes mellitus and was treated with insulin. In December, 1990, high plasma ACTH and low plasma cortisol levels were noted. In June, 1991, hyperpigmentation of the lips, oral mucosa, and skin was noted and she was diagnosed as having idiopathic Addison's disease, for which she was treated with hydrocortisone.

Patient 10. A 56-year-old female was diagnosed in August, 1989 as having hyperpigmentation of the buccal mucosa and lips. She was diagnosed as having idiopathic Addison's disease and was treated with hydrocortisone. Addison's disease was considered due to idiopathic atrophy because she had no history of tuberculosis. She was also treated with methimazole for Graves' disease from 1988.

Patient 11. A 48-year-old female suffered from hyperpigmentation and lassitude in 1989. She was diagnosed as having Addison's disease, and treated with hydrocortisone from April 1992. Addison's disease was considered due to idiopathic atrophy because of a history of myasthenia gravis, and of a complication of idiopathic hypoparathyroidism.

Patient 12. A 43-year-old female suffered from hyperpigmentation in 1977 and lassitude in 1979 . She was diagnosed as having Addison's disease and treated with hydrocortisone from August, 1979. In August, 1987, she suffered premature ovarian failure and was diagnosed as having poly-endocrinopathy with idiopathic Addison's disease.

\section{Results}

Twenty-three adrenal CT scans were obtained from eight patients (patients 1-8, Table 1) with Addison's disease secondary to tuberculosis. Of 


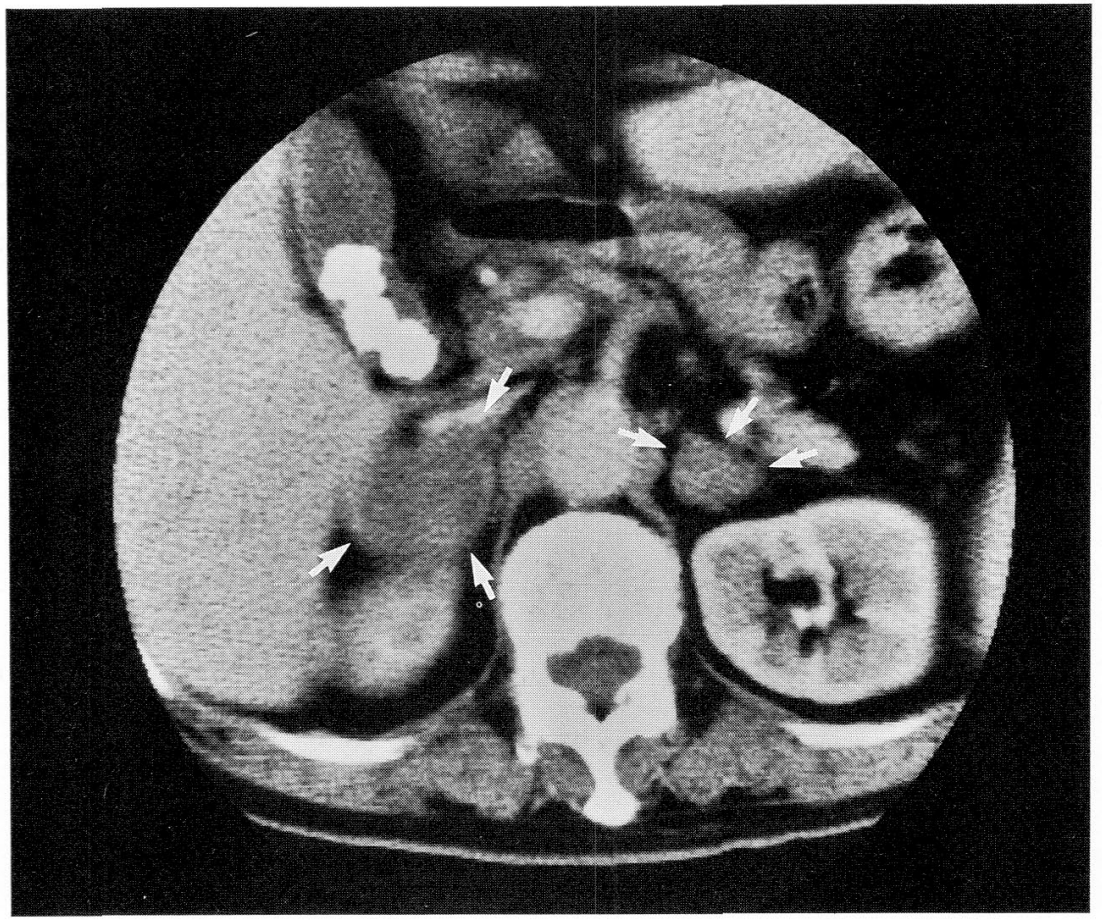

Fig. 1. Adrenal CT scan of patient 1 (1984). Bilaterally enlarged glands are indicated by arrows. The low-density area in the central part of the right gland may be necrotic.

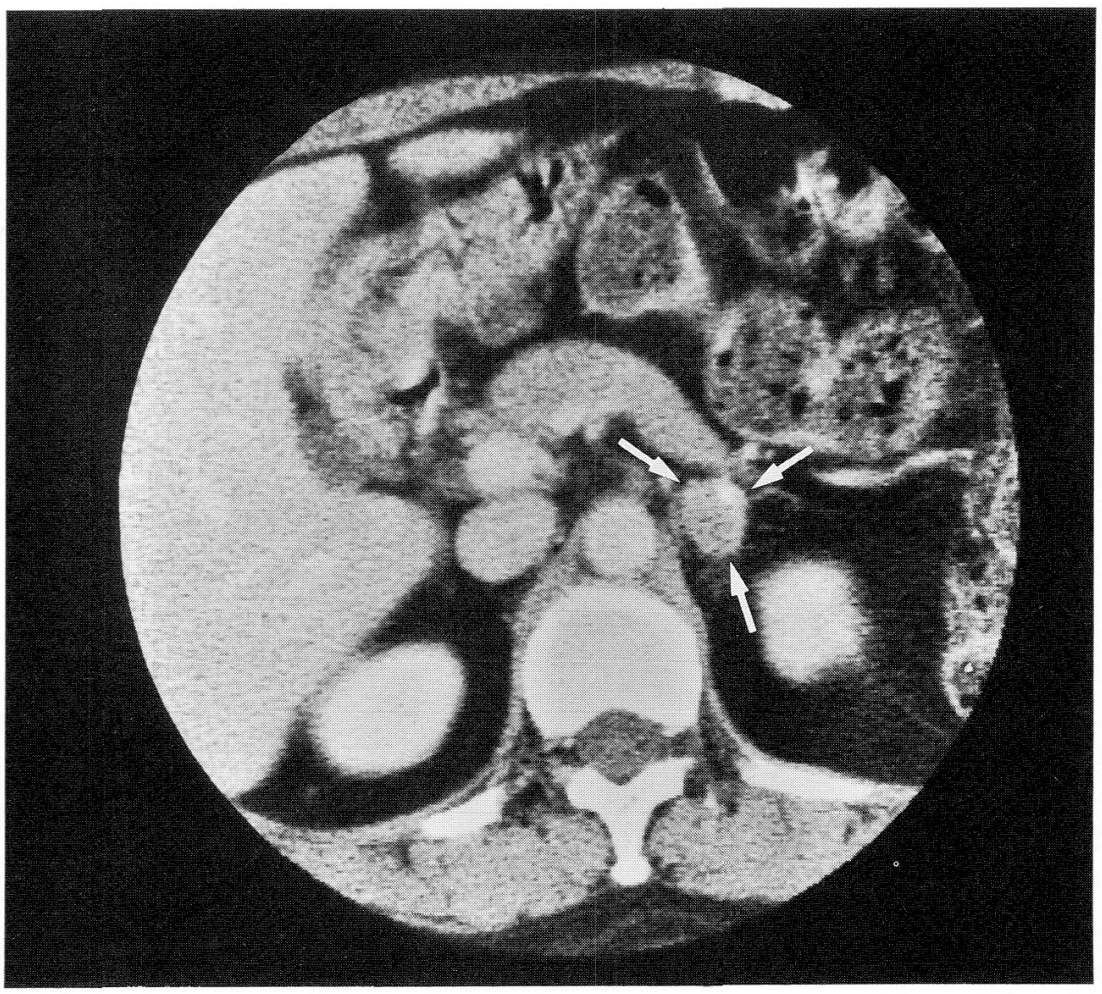

Fig. 2. Adrenal CT scan of patient 1 examined in July, 1991. This enlarged left adrenal gland is marked with an arrow, although it is small when compared with 1984 (Fig. 1). The right gland was too small to be shown by CT. 


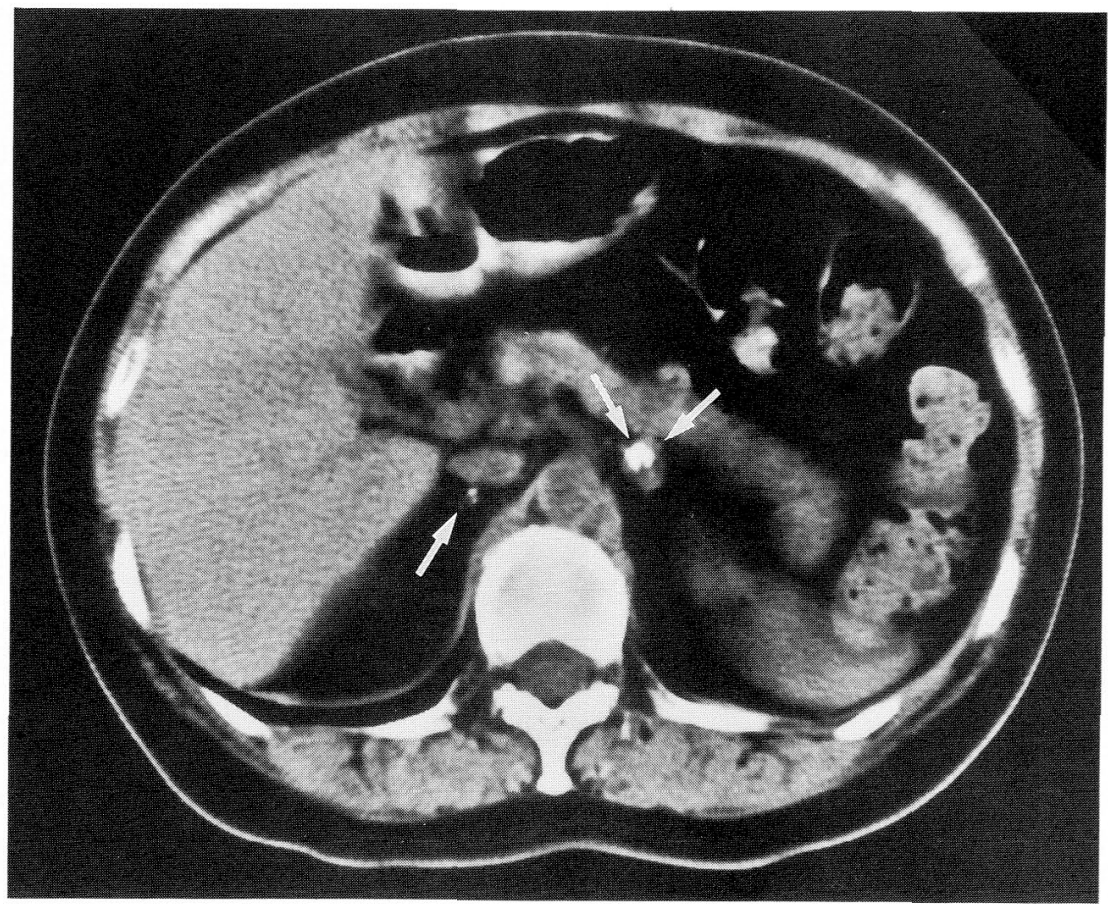

Fig. 3. Adrenal CT scan of patient 5 examined in February, 1989. Bilateral adrenal glands (shown by arrows) were atrophied and the left gland was calcified.

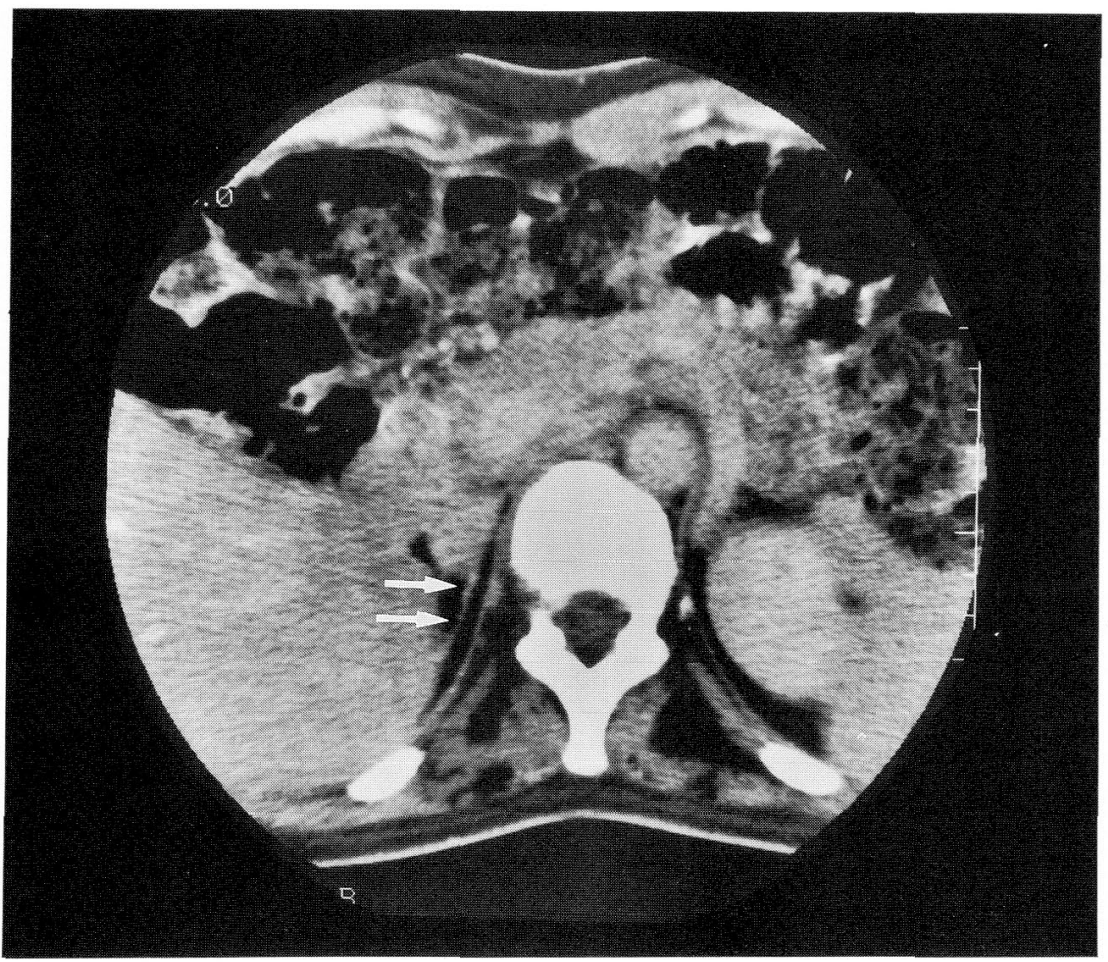

Fig. 4. Adrenal CT scan of patient 9 examined in July, 1991. Bilateral adrenal glands (shown by arrows) were atrophied. 
four patients examined within two years of Addison's disease onset, patients 1-3 (75\%) were found to have bilaterally enlarged glands (Fig. 1), and the rest (patient 4) had a unilaterally enlarged gland. During the four years after onset, at least one adrenal gland in all patients examined (patients 1-6) became enlarged (Fig. 2). After more than four years, the gland atrophied (Fig. 3) or was slightly reduced in size. Adrenal calcification, observed in 5 of 8 patients with tuberculous Addison's disease, was not related to disease duration. The calcified adrenal glands became only slightly smaller, if at all, as shown in patients 4-6, suggesting that adrenal calcification represents the final stage in adrenal inflammation.

Patients 9-12 were diagnosed as having idiopathic Addison's disease. Their adrenal glands were no longer bilaterally visible by the time of disease onset (patients 9 and 10) (Fig. 4). Adrenal calcification was not observed in any of the four patients.

\section{Discussion}

In a recent Japanese survey study of about 128 patients with Addison's disease from 1982 to 1986 , the incidence of tuberculous Addison's disease was $59 \%$, and of idiopathic Addison's disease was $33 \%$ [14]. We compared the findings in adrenal CT scanning for these two major causes of Addison's disease. At least one gland was enlarged in patients with tuberculous Addison's disease during the initial four years following disease onset. Particularly during the first two years, bilateral adrenal glands were enlarged in three quarters $(75 \%)$ of patients who had tuberculous Addison's disease. On the other hand, the adrenal gland in idiopathic Addison's disease atrophied at onset. Our findings thus showed the usefulness of CT scanning for differentiating tuberculous and idiopathic Addison's disease during the initial four years-the most important period for diagnosis. Bilateral adrenal glands eventually atrophied even in tuberculous Addison's disease, making a differential diagnosis difficult more than four years after disease onset. CT scanning is the most sensitive imaging method available for detecting calcification [15]. Adrenal calcification may be another useful clue in tracing pathogenesis, although it does not indicate the disease onset and is not observed in all tuberculous Addison's patients. Adrenal calcification may also suggest other re- latively rare diseases such as histoplasmosis, cancer, and bleeding, but not idiopathic adrenal atrophy.

It may be argued that hormone supplements alter CT findings in some way. However, since in Addison's disease the adrenal gland is already atrophied or occupied by granulomatous tissue, the influence of small supplemental doses of glucocorticoids appears neligible. Antituberculous treatment may modify the CT findings, however. In our study, patients 1 and 3 were treated with antituberculous drugs for short periods: 8 months in patient 1 and after CT scanning in patient 3 . Our conclusions are therefore not influenced by antituberculous treatment. In addition to hormone supplements, patients with active tuberculous adrenalitis also receive antituberculous treatments since those treated early my possibly recover adrenal function [9-11]. Although our results do not fully support the above assumption, bilaterally enlarged glands may be a good indicator for initiating antituberculous therapy. In this context, physicians should be aware of the occurrence of adrenal tuberculosis in which adrenal insufficiency occurs without signs of tuberculosis. This could be demonstrated by enlarged glands seen in CT scanning or directly by laparotomy [9]. Other etiologies of Addison's disease with enlarged adrenal masses are also possible. Although it was rarely reported in Japan, histoplasmosis and blastomycosis cause granulomatous adrenalitis disease $[4,16]$. Adrenal metastasis in cancer also causes Addison's disease with an enlarged adrenal mass.

In summary, adrenal CT scanning is clinically useful in distinguishing between idiopathic and tuberculous Addison's disease: a finding having important implications in terms of initiating treatment.

\section{Acknowledgments}

This study was supported in part by a grant for the treatment of intractable diseases from the Japanese Ministry of Health and Welfare. Zhong Hua Sun is a doctor from the People's Republic of China studying in Japan under a grant from the Japan-China Medical Association. We thank Ms. Jun Setoguchi for editing this manuscript. 


\section{References}

1. Barker NW (1929) The pathologic anatomy in twenty-eight cases of Addison's disease. Arch Pathol 8: 432-450.

2. Guttman PH (1930) Addison's disease. Arch Pathol 10: 742-785 and 895-935.

3. Frenkel JK (1960) Pathogenesis of infections of the adrenal gland leading to Addison's disease in man:The role of corticoids in adrenal and generalized infection. NY Acad Sci 393-439.

4. Doppman JL, Gill JR, Nienhuis AW, Earll JM, Long, Jr JA (1982) CT findings in Addison's disease. J Comput Assist Tomogr 6: 757-761.

5. McMurry Jr JF, Long D, McClure R, Kotchen TA (1984) Addison's disease with adrenal enlargement on computed tomographic scanning. Am J Med 77: 365-368.

6. Wilms GE, Baert AL, Kint EJ,Pringot JH, Goddeeris PG (1983) Computed tomographic findings in bilateral adrenal tuberculosis. Radiol 146: 729-730.

7. Huebener K-H, Treugut H (1984) Adrenal cortex dysfunction: CT findings. Radiol 150: 195-199.

8. Yamakita N, Yasuda K, Goshima E, Murayama M, Murase $\mathrm{H}$, Minamori $\mathrm{Y}$, Ishizuka T, Miura K (1986) Comparative assessment of ultrasonography and computed tomography in adrenal disorders. Ultrasound in Med E Biol 12: 23-29.
9. Vita JA, Silverberg SJ, Goland RS, Austin JHM, Knowlton AI (1985) Clinical clues to the cause of Addison's disease. Am J Med 78: 461-466.

10. Coleman EN, Arneil GC (1962) Acute tuberculous adrenocortical failure with clinical recovery. Lancet Apr 28: 886-888.

11. Annear TD, Baker GP (1961) Tuberculous Addison's disease. A case apparently cured by chemotherapy. Lancet Sept 9: 577-578.

12. Osa SR, Peterson RE, Roberts RB (1981) Recovery of adrenal reserve following treatment of disseminated South American Blastomycosis, Am J Med 71 : 298-301.

13. Montagne J-P, Kressel HY, Korobkin M, Moss AA (1978) Computed tomography of normal adrenal glands. Am J Roentgenol 130: 963-966.

14. Takeda R (1987) Annual report of the Ministry of Health and Welfare "Disorders of Adrenal Hormones" Research Committee, Japan, 1987. 3-4.

15. Siegelman SS, Zerhouni EA, Leo FP, Khouri NF, Stitik FP (1980) CT of the solitary pulmonary nodule. Am J Roentgenol 135: 1-13.

16. Halvorsen RA Jr, Heaston DK, Johnston WW, Ashton PR, Burton GM (1982) CT guided thin needle aspiration of adrenal blastomycosis. $\mathrm{J} \mathrm{Com}$ put Assist Tomogr 6: 389-391. 